\title{
Preventive Rehabilitation in Leprosy
}

\author{
Mrs. S. KARAT, M.B.B.S., F.R.c.s. (EDIN.) \\ Consultant Surgeon, Schieffelin Leprosy Research Sanatorium, \\ B.O. Karigiri, via Katpadi, N.A. District, S. India \\ Senior Lecturer in Surgery, Christian Medical College and Hospital, Vellore, N.A. District, S. India
}

PART III

PRINCIPLES OF PRACTICAL APPLICATION

The overall strategy of approach to the problem of leprosy has changed drastically during the past decade. The era when sanatoria, care homes or leprosy settlements seemed to be the mainstay has given way to survey, examination and domiciliary treatment and leprosy control programmes.

To get a patient to the stage where the disease is 'arrested' and to reduce the reservoir of infection in the community and thus reduce the incidence of the disease in the next generation is basically a right approach to any infectious disease. Yet of ten the pendulum seems to have swung too far. In the planning of such programmes and the facilities offered therein, the care of the individual patient is of ten ignored.

The approach to the problem of individual patient care and care of his disabilities in such a leprosy treatment and control programme is vastly different from the one that is adopted in sanatoria with long-term patients. This approach is largely untried and is not provided for in the majority of such programmes.

We have already stated that preventive rehabilitation should be our first aim. Returning to his home and his usual occupation with a knowledge and discipline to preserve his anaesthetic limbs, is not only a practical solution in the developing countries, but also ideal for a leprosy patient whose special need includes social acceptance and the need to retain his family ties.

At the Schieffelin Leprosy Research Sanatorium in the domiciliary treatment and leprosy control programme a method of individual patient care has been planned and evolved during the past 3 years with great success. The domiciliary treatment programme undertaken by the institution in the Gudiyatham Taluk covers an area of 481 square miles with an estimated mid-year population in 1967 of 410,000 . Of these, 90,000 are in urban areas. We have so far covered the rural area in terms of census and survey and examination of over $90 \%$ of the rural population. So far 7,100 patients have been registered and treated at $4 \mathrm{l}$ peripheral clinics in the villages throughout the taluk. The attendance rate is now at $75 \%$. The main hospital caters for short-term patient care for conditions needing intensive medical and surgical care.

There are 2 distinct aspects to the carrying out of a comprehensive programme of preventive rehabilitation and re-education for resettlement. First is the principle and methodology adopted in dealing successfully with the problem of each patient with either early or severe disability.

Second is the problem of practical application of such methods to serve patients in a domiciliary treatment programme, where a large number of patients are scattered over a wide area and have only short periods of contact with hospital personnel.

INDIVIDUAL CARE

'Living with anaesthetic limbs' is the chief disability in leprosy. The life-long discipline and constant vigilance needed to live with anaesthetic limbs requires, firstly, the patient's 
intelligent understanding of the problem. Thus group and individual education plays a prominent role. The second requirement includes both practice and discipline that is necessary to translate this knowledge into daily activities.

The problem of communication where the majority of patients are mostly illiterate needs special study. Simple audio-visual aids and practical demonstrations repeated over and over again, each time varying the theme and method of approach to break the monotony are important. Practical illustrations using an injured limb or a 're-educated' patient as a live subject of ten has quite an impact. When such education is combined with intensive care of even minimal injury or trophic ulceration of anaesthetic limbs, the large majority of patients respond eagerly and acquire sound knowledge and understanding of the problem of anaesthesia.

The problem of application of this knowledge in the day-to-day activities is the most important step in rehabilitation. In our experience, we have found that quite a large majority of patients need a period of intensive practical training with individual supervision to teach them to work with their anaesthetic limbs without further injury. Such a period of training has given excellent results and the majority of patients do not need more than one such training period.

The organisation of such a programme, with individual and group education, followed by intensive, individual, practical training courses to cover the large number of widely scattered patients in a typical leprosy control programme needs a new approach. Analysis of disability among the patients in control programmes has given figures varying from $20 \%$ to $25 \%$. In a typical domiciliary treatment clinic most of the patients get the medications once in 3 months. It is then possible to group the disabled patients to attend the clinic on a special 'rehabilitation day' when a little less than a quarter of the patient-load of the clinic will be invited to attend. To this clinic should be sent a team consisting of a social worker, physiotherapy technician, and a cobbler. They can examine the limbs, apply plaster immobilisation when needed, issue footwear, use audio-visual aids and practical demonstrations and supply adapted implements suitable for routine work and activities of daily living. Careful recording of disabilities and injuries sustained and the patients' occupational status is important to enable intelligent organisation and planning of such a programme.

Those who are found to be sustaining repeated injuries and those who are either underemployed or unemployed due to their disabilities need to be brought to the main hospital for intensive practical training courses.

The programme at the main hospital needs to be carefully planned and organised to maintain maximum efficiency and to use minimum time. It is important that a leprosy hospital is planned to cater for anaesthetic limbs both in its construction and in its daily routine and discipline. Whereas such planning is universally accepted for other groups of disabled patients such as paraplegics or spastics, this is still a new approach in leprosy where anaesthetic limbs are such a devastating disability to patients.

It is thus important for example that in a leprosy hospital no patient with anaesthetic feet is ever seen without suitable microcellular rubber footwear at any time. Daily morning inspection of hands and feet and daily oil massage for dry skin should be a part of the daily routine. Every patient should learn suitable first aid methods to deal with fresh injuries, blisters or fissures. Every patient should be encouraged during meal time to use protected utensils and a spoon.

In addition to these routine activities in hospital, practical classes in the activities of daily living, like cooking, washing and cleaning need to be conducted for small groups of patients. In our experience we have found that at least 8 to 10 such classes are essential for each patient. Vocational re-training demands a lot of time and patience from the rehabilitation team. But once a patient is 'broken in' and gets the idea and gets accustomed to the use of adaptations, one has the gratifying prospect of having solved a life-long problem. Effective vocational re-training, in our experience, needs 
about a month of regular work under daily supervision. A farmer, for instance, needs to carry out the entire range of activities involved in tending his farm, using the same methods and implements that he is likely to use when he returns home.

In dealing with anaesthetic limbs, the emphasis has often been on adaptations and modifications of handles and tools. It has been our experience that important as these are and often essential for a significant number of patients, by far the most important requirement is the patient's understanding of the problem of anaesthesia and a period of intensive practical training under supervision. Large numbers of these patients have returned to full employment with no further incidence of trophic ulceration. What is significant is that a large number of them do not use the adaptations and modifications recommended and supplied to them once they leave the hospital and go to their usual places of work. Often a simple device like a piece of cloth was used and found adequate to protect the hand against injury by heat or pressure. We have thus found it important to shift our main emphasis from adaptations and modifications of the tools to the education and training of the patient.

\section{ACKNOWLEDGEMENTS}

I am grateful to the Leprosy Mission, London, the American Leprosy Missions Inc., New York, and the Swedish Red Cross, Stockholm, for continued encouragement and financial support.

I would like to thank my colleagues, particularly those in the Physiotherapy and Occupational Therapy Departments for conscientious and devoted service, which has enabled us to study these problems and find some of the answers.

\section{BIBLIOGRAPHY}

BRAND, P. W. Life after Leprosy through Rehabilitation. Rehabilitation Literature, 21, 8, Aug. 1960.

HEMERIJCKX, F. Report on the activities of the Belgian Leprosy Centre, Polambakkam (1955-1958).

Noordeen, S. K. and sRinivasan, H. Epidemiology of Disability in Leprosy. Int. .J. Lepr. (1966), 34, 159-169.

Wilson, E. An Experiment in Agriculture. Report of Intensive Course for Leprosy Patients in the Gudiyatham Control Programme. Paper read at the International Leprosy Seminar at Agra, India, 1967.

wORLD HEALTh ORganisation. Scientific Meeting on Rehabilitation in Leprosy. Wld. Health Ord. Techn. Rep. Ser., 1961, 221. 